\title{
RESEARCHING HUMOR ON THE INTERNET
}

\section{Liisi Laineste}

Collecting jokes on the Internet is becoming more and more useful, and one might say even unavoidable. The renewed nature of jokes (short, electronically distributed in addition to oral circulation, some jokes created only for electronic media (see Ellis 2001) etc) requires renewed methods for collecting and processing the data. Further than that, the Estonian Internet has some special advantages for collecting various folklore, including jokes.

Few years after the WWW was established and began to grow, folklorists have used it as a source for their studies. Less frequent are meta-studies that analyse the theoretical concepts and practical problems are involved in this new line on research. Guidelines for this type of folkloristic research are yet unexisting. This brief overview does not attempt to do that, either, but points to the necessity to start forming and discussing the guidelines. Humour and jokes in particular are a good starting-point for this discussion because in a way humour is a "founding member" of the Internet. The Internet was created as a means of serious communication, but became popular mostly due to its entertaining nature. But the biggest entertainer, as we all know, is humour and its various forms of appearance. The internet owns its social nature and exponential growth mainly to the playful and entertaining atmosphere generated by humour (see Kirschenblatt 1996).

The Internet holds basically two types of research material: static and dynamic. The static material lacks the social clues of immediate interaction. These clues are otherwise quite inherent in the Internet that claims to be a new form of orality (Ong 1988). Of course the wider social background is still there, but features of interactivity mostly missing. It is cumulative and (if the site-owner or administrator still maintains it) all the once added material is accessible at any later point of time. The dynamic material is interactive, ie chatroom-type joke portals. But also this, as does the static material, retains its history and is thus almost like live conversation but 
traceable and open to detailed analysis (a feature that often is missed in studies of verbal communication). Jokes appear both on the static and dynamic sites.

The Internet is now widely accepted as a perfect environment for preliminary research, a starting point for later research done with conventional methods and groups. Part of this belief is founded on true presuppositions - the material found in the Internet is quickly accessible and very varied. But it is false to believe that it is unsuitful for serious research. Even more, research in the Internet must be recognized among other established branches of research. We cannot deny that the distinctive environment and virtual communication etc are attaining special features that need to be studied on their own, using suitable specially developed methods (Baym 1993, Kirschenblatt 1996, Hine 2000). In February 2004, a special issue of The Information Society edited by Nancy Baym will tackle the questions of Internet research and its disciplinary boundaries.

The Estonian language Internet has its own special advantages when it comes to research. Its reasonable size compared to the English language material is excellent in two ways: first, there is little chance to get lost in the material, and second, it gives quite a good overview of all possible angles of the problem under research. In a way, the material can even be complete (compared to other means of data collecting). For example, joke sites (both dynamic and static) can be under constant surveillance for relevant jokes. It is nearly impossible to overlook the bigger and more popular sites. Smaller sites are listed in the portal http.//www.neti.ee. Many start their acquaintance with the Internet by making an elementary (mostly static) site introducing themselves, very often also adding a handful of favourite jokes. The problem with such sites is their relatively short lifetime, so that doing research with the material and requires that the sources have been stored in a database for later retrieval. But generally it is easier for a researcher to use material from static sites. Jokes are usually all in one place (sometimes categorised by subjective liking or more objective categories) and simple copy-paste method for archiving them in the electronic database can be used. The procedure has to be done just once, unless the site gets updated, which is seldom the case. Dynamic sites need better prepared method for archiving the jokes. 
Estonian Literary Museum has a growing electronic database of contemporary humour dating back to 1996. Jokes are collected from both dynamic and static sites. A preliminary version for end-users can be found on the site http://www.folklore.ee/ liisi/raamid.html. A program is under construction that would make collecting jokes easier, aimed at collecting the jokes from dynamic sites. First, it checks all listed humour sites and entertainment portals for new updates: the jokes will be collected daily from all major daily updated humour sites, categorised and entered into humour database. At the moments there are different programs for the mentioned tasks. They must be integrated for a smoother joke collection process. Retrieval of jokes from the database has to be made more userfriendly as well.

After the jokes have been entered into the database, there are some advantages to electronically stored material worth mentioning. But we must not forget that the material reflects still in great part Internet culture with its distinctive features. The resemblance with oral communication exists but it cannot be taken for face to face interaction. Possible lines of research include:

1. Examining the whole database or sections of it without consuming too much time on retrieval of the material

2. Analysing the material by dates. For example, when the date is given (and for most part it is), one can find out about waves of jokes connected to dates or events, or changes in social reality, attitudes etc when analysing a sufficiently wide period of time

3. Finding out any material on a single feature or a combination of them (needs skills for query building)

4. The results are not dependent upon one single respondent or a restricted group of people, but a large amount of instances. The analysis is based on varied, numerous and more objective material

5. Combining qualitative and quantitative methods. Statistical general analysis will support more detailed and deep qualitative analysis. Quantitative analysis serves well as an entering-point into the body of material and state the hypothesis. 
Still, the methods for analysing the data from the Internet either qualitatively or quantitatively are left mostly to the researchers imagination. Rules are missing and that results in a quagmire of nearly all methods that are suitable for trying. Especially when it comes to qualitative analysis, appropriate methods should be developed. An analysis guided on the jokes from the major Esotnian portal http://www.delfi.ee (Laineste 2003) used simple statistics (programs Excel for general data like means and sums, and Statistica for t-tests) for quantitative analysis (see also graphs, pages 10, 11 and 14). For more detailed and social background analysis, I used critical discourse analysis developed by Fairclough and elaborated by Wodak. Critical discourse analysis consists of three levels of investigation, as defined by Fairclough (1993): description, interpretation and explanation. The method is perhaps too specifically aimed at pointing to the discourses of power in the society and even though jokes are an anti-discourse to power (Davies 2003), the method is more suited to e.g. analysis of newspaper articles than more spontaneous humorous texts.

The main message of the short overview is thus to point to the growing need to institutionalise Internet research and develop suitable methods for the data it contains.

\section{Comments}

This article was written with support from the ETF grant No. 4935 and introduces work carried out within this.

\section{References}

Kirschenblatt-Kimblett, Barbara 1996. The Electronic Vernacular. Marcus, George (ed.). Connected: Engagements with Media. Late editions, 3. Chicago: University of Chicago Press, pp. 21-65

Ong, Walter J. 1988. Orality and Literacy: The Technologizing of the Word. New Accents. Ed. Terence Hawkes. London \& New York: Methuen.

Baym, Nancy K. 1993. Interpreting Soap Operas and Creating Community: Inside a Computer-Mediated Fan Culture. Journal of Folklore Research, Vol. 30, No. 2/3, pp. 143-177. 
Hine, Christine 2000. Virtual Etnography. London \& Thousand Oaks: SAGE.

Fairclough, Norman 1993. Critical Discourse Analysis and the Marketization of Public Discourse: The Universities. Discourse and Society, Vol. 4, No. 2, pp. 133-168.

Daveis, Christie 2003. Jokes that follow mass-mediated disasters in a global electronic age. Narvaez, P. (ed.). Of Corpse: Death and humor in folklore and popular culture. Logan (Utah): Utah State University Press, pp 15-34.

Laineste, Liisi 2003. Take it With a Grain of Salt: The Kernel of Truth in Topical Jokes (http://haldjas.folklore.ee/folklore/vol21/ - January 23, 2004).

Ellis, Bill 2001. A Model for Collecting and Interpreting World Trade Center Disaster Jokes. New Directions in Folklore. Vol. 5, pp. 1-12. 